\title{
Erythroderma: A Manifestation of Cutaneous and Systemic Diseases
}

\author{
Authors: \\ Sindi Hoxha, *Monika Fida, Ritjona Malaj, Ermira Vasili \\ University Hospital Center 'Mother Teresa' Tirana, Tirana, Albania \\ *Correspondence to monikafida@gmail.com \\ Disclosure: $\quad$ The authors have declared no conflicts of interest. The institutional ethical board of \\ UMT approved this study. \\ Received: $\quad 17.10 .19$ \\ Accepted: $\quad 12.02 .20$ \\ Keywords: $\quad$ Emergency, erythroderma, psoriasis. \\ Citation: \\ EMJ Allergy Immunol. 2020;DOI/10.33590/emjallergyimmunol/19-00182
}

\section{Abstract}

Introduction: Erythroderma, or generalised exfoliative dermatitis, is a rare inflammatory disorder characterised by generalised erythema, involving more than $90 \%$ body surface area accompanied by a variable degree of scaling.

Objectives: This retrospective study aimed to determine characteristics of erythroderma as a marker of cutaneous and systemic disease and to identify the underlying causes of this condition.

Materials and methods: Hospitalised patients diagnosed with erythroderma at the dermatology and venereology department of UHC 'Mother Teresa' from 2012-2017 were selected for this study. Epidemiological, clinical, laboratory, and histological data of these patients were electronically compiled and analysed using SPSS $^{\odot}$ software (IBM, Armonk, New York, USA).

Results: 116 patients were diagnosed with erythroderma. Of these, 43.1\% were female and 56.9\% were male. The average age of onset was 55.1 years. A variable hospitalisation period was observed from 1-49 days. Previous episodes of erythroderma were indicated in $11.2 \%$ of cases, and $29.3 \%$ of cases appeared as emergencies. The most common cause of erythroderma was exacerbation of pre-existing dermatoses, namely psoriasis (53.4\%), eczema (3.4\%), and dermatitis (10.3\%). Drug hypersensitivity reactions were evidenced in $4.3 \%$ of cases. In $16.4 \%$ of cases, the cause of erythroderma was undetermined. This study demonstrated a high percentage of secondary erythroderma to a pre-existing cutaneous pathology, psoriasis in $53.4 \%$ of cases, and a low percentage of primary erythroderma.

Conclusions: Erythroderma can be a manifestation of systemic and cutaneous diseases, but mostly erythrodermic psoriasis. Often it presents as a life-threatening emergency. The condition masks the primary pathology lesions, making it difficult to establish the correct diagnosis of the underlying aetiology. However, biopsy provides a positive correlation between clinical findings and anatomopathological diagnosis. 


\section{INTRODUCTION}

Erythroderma, or generalised exfoliative dermatitis, is a rare inflammatory disorder characterised by generalised erythema, involving more than $90 \%$ of the body surface area accompanied by a variable degree of scaling. Erythroderma can be a primary condition, when the cause is unknown, or a secondary condition, caused by known diseases. The age of its onset is related to its underlying aetiology, which in most cases are skin diseases or disorders, hypersensitivity towards drugs and medications, systemic diseases associated with cutaneous erythema, and in rare instances, malignancies. Erythroderma predominates in males and most commonly manifests in older ages. It is a potentially life-threatening disease as it alters cutaneous functions, therefore erythrodermic patients require hospitalisation, rigorous monitoring, and follow-up. Determining the underlying cause of erythroderma is important in choosing the right treatment for these patients.

\section{AIM}

This retrospective study aimed to identify the underlying cause of erythroderma and to determine for the first time its epidemiological, clinical, and laboratory features in Albanian patients with erythroderma.

\section{MATERIALS AND METHODS}

The authors conducted a retrospective analysis of a total of 116 patients diagnosed with erythroderma at the dermatology and venereology department of UHC "Mother Teresa" from 20122017. Diffuse erythema, (over $70-90 \%$ of body surface) accompanied by various degrees of scaling and pruritus, were used as the diagnostic clinical criteria. Epidemiological characteristics, clinical symptoms, performed examinations, skin biopsy, immunophenotyping (whenever indicated), and follow-up information were collected. Emergency and relapse cases were also highlighted when this information was available. The collected data were electronically analysed using SPSS v.19.

\section{RESULTS}

\section{Epidemiology}

During this 6-year study, 116 patients were diagnosed with erythroderma and admitted to the authors' department. The age of the patients varied from 2-86 years, with a mean onset age of 55.1 years and the highest incidence of erythroderma occurring in the 61-70 age group (26.7\%; $n=31$ ). There was a slight male predominance with a male to female ratio of 1.32:1.00 (57.0\% male versus $43.0 \%$ female). There was no change regarding the age of onset of erythroderma in males and females using the independent t-test. Both groups exhibited a highest frequency of erythroderma onset in the seventh life decade. Considering all cases, the total number of patients hospitalised during the period of July and August was higher compared to other months (16.4\% versus $14.7 \%$, respectively).

\section{Clinical Parameters}

Patients were hospitalised in the department of dermatology for an average of 12.6 days (day range: 1-49 days) following onset of erythroderma. A shorter hospitalisation period was observed in patients with drug-induced erythroderma and a longer hospitalisation period in erythrodermic psoriasis patients. A history of previous erythrodermic episodes was noted in $11.2 \%$ of cases $(n=13), 10$ of which were caused by psoriasis, with the other three being caused by other pathologies, namely chronic eczema, subcorneal pustulosis, and chronic dermatitis. The majority of admissions were planned admissions, however $29.3 \%$ of all the cases presented as emergencies.

\section{Clinical Findings in Admission}

In the first clinical examination, generalised erythema, scaling, and pruritus were identified. Scaling and erythema are constant identifying markers of the pathology and will be found in $100.0 \%$ of cases. Pruritus was detected in all patients, and $34.5 \%$ of cases $(n=40)$ had fever $>38.5{ }^{\circ} \mathrm{C}$ during the onset of the erythrodermic episode. Changes in the nails, psoriatic arthritis, and palmoplantar keratoderma were findings that prevailed in patients with erythrodermic psoriasis in almost $27.6 \%$ of cases $(n=32)$ (Figure 1$)$. 


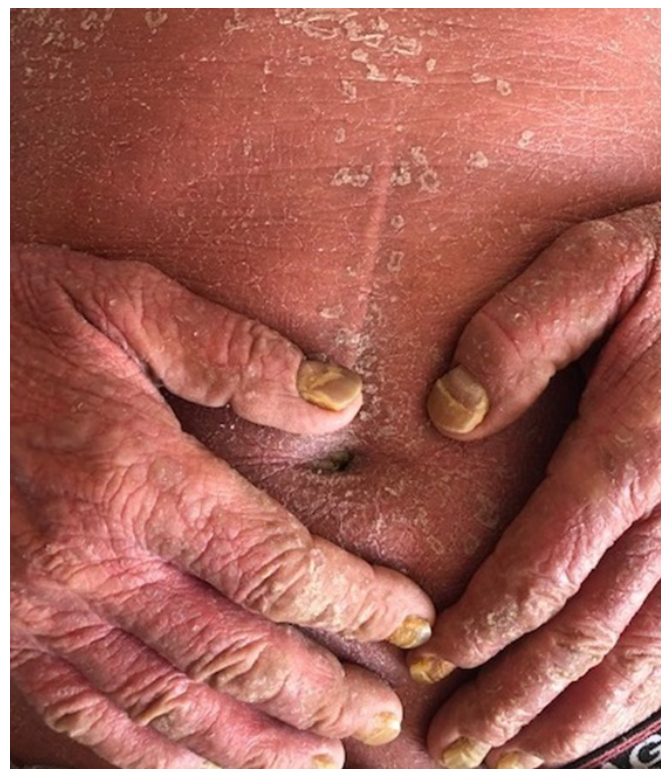

Figure 1: One of the patients with erythroderma caused by psoriasis vulgaris.

(This photo was taken and used in thestudy with the patient's permission).

\section{Laboratory Findings}

The most common abnormalities found in the patients included increased erythrocyte sedimentation rate and C-reactive protein in 93.1\% of cases $(n=108)$, leukocytosis in $43.9 \%$ of cases $(n=51)$, and decreased haemoglobin in $30.2 \%$ of cases $(n=35)$.

Cutaneous biopsy was performed in 105 patients (90.5\%). In the remaining 11 cases, when the cause of erythroderma was clear at the time of the examination, biopsy was unnecessary. This group included six cases previously diagnosed with psoriasis and five cases of generalised erythroderma appearing after the use of a new drug.

Histopathological examination was decisive for concluding the diagnosis in 86/105patients who received biopsy. The results were as follows: psoriasis vulgaris (53.4\%) in 62 cases, psoriasiform dermatitis (6.9\%) in eight cases, subcorneal pustulosis (5.2\%) in six cases, drug hypersensitivity (4.3\%) in five cases, chronic eczema (3.4\%) in four cases, chronic dermatitis (2.6\%) and erythema multiforme (2.6\%) in three cases each, pityriasis rosea (1.7\%) and pytiriasis rubra pilaris (1.7\%) in two cases each, and spongiotic dermatitis (0.9\%) and ichthyosis $(0.9 \%)$ in one case each. Nonspecific histopathological features were observed in 19 cases $(16.4 \%)$.

Final diagnosis was based on evaluation of the clinical, biochemical, and histological findings, as well as the development of erythroderma in each individual patient. The most common underlying cause was exacerbation of pre-existing dermatoses, including psoriasis in $59.0 \%$ of the cases, subcorneal pustulosis in $5.2 \%$, pityriasis rubra pilaris $1.7 \%$, chronic dermatitis in $3.4 \%$, and pityriasis rosea in $1.7 \%$. Drug hypersensitivity was seen in $4.3 \%$ of cases and no cause could be identified in $16.4 \%$ of cases. Diagnosis of idiopathic erythroderma was made in patients who manifested an extended condition with the typical clinical signs of generalised erythema, severe pruritus, and scaling. In these cases, the significance of histopathological examination is emphasised. The most important differential diagnosis in idiopathic erythroderma is cutaneous lymphoma, especially in older adult males with an extended and relapsing course of pruritic erythroderma. Close monitoring and repeated biopsy in cases with no found cause of erythroderma may reveal an undiagnosed cutaneous T-cell lymphoma (CTCL). In these cases, histopathology results were nonspecific, and as such were diagnosed as idiopathic erythroderma. 
The relationship between a drug and drug-induced erythroderma was decided from a carefully conducted anamnesis with the patient, monitoring the intake of a suspected drug in the days prior to the onset of erythroderma and clearing of the cutaneous manifestations following discontinuation of the specific drug.

On follow-up, no cases of death were recorded due to erythroderma or its underlying causes. Relapse was observed in patients with chronic dermatitis and ichthyosis, but not in patients with a drug-induced erythroderma. During the study period, $76.4 \%$ of the patients with psoriasis were hospitalised for the second time.

\section{DISCUSSION}

In this study, 116 cases with erythroderma were collected within a 6-year periodfrom January 2012-July 2017. The highest number of cases with erythroderma were recorded in 2014 (24.1\%; $\mathrm{n}=28$ ). Erythroderma usually occurs in the sixth decade of life, cited in prior studies by Cesar et al., ${ }^{2}$ Humaira T et al., ${ }^{3}$ Li et al., ${ }^{4}$ Khaled et al., ${ }^{5}$ Fernandes et al., ${ }^{6}$ and Rym BM et al. ${ }^{7}$ The largest occurrence is reported in the sixth life decade with a male predominance. ${ }^{4-8}$ These study results coincide with the literature regarding the gender distribution of erythrodermic patients, however it was noted that the largest occurrence of erythroderma was observed in the seventh life decade (Table 1). ${ }^{2-10}$

The highest total number of patients admitted were during the months of July $(16.4 \% ; n=19)$ and August (14.7\%; $n=17)$. This result doesn't correlate with findings by Hulmani et al., in which most of the cases of erythroderma (30.0\%) were in December and January. This could be related to the underlying aetiology of erythroderma in that most cases are linked to psoriasis, which shows periods of exacerbation during the winter months. Unlike this conclusion, the result of the present study correlated with Okoduwa et al.," which evidenced exposure to ultraviolet radiation and sun as an aggravating factor of erythroderma, explaining the highest frequency of cases being during the summer months of July and August.

The onset of erythroderma is gradual and insidious. ${ }^{2,4,5,8,9}$ Cases of hypersensitivity to medications, with an unexpected onset and a faster resolution, are excluded from this definition. ${ }^{2,4,5}$ Similar results were indicated in this study. Drug-induced erythrodermic cases were associated with a shorter hospitalisation period while the erythrodermic psoriasis cases marked the longest hospitalisation periods observed.

Of the cases, $11.2 \%$ appeared recurrently, while 29.3\% appeared as emergencies. Psoriasis was the most common aetiology in both groups (76.9\% and 59.0\%, respectively).

The diagnostic approach of patients with erythroderma depends on their previous dermatological history. ${ }^{2}$ Patients with a history of dermatological disorders may develop erythroderma during an exacerbation of their underlying pathology. ${ }^{2}$ The aetiologic diagnosis is generally clear in these cases. On the contrary, final diagnosis is the result of clinical, biochemical, and histopathological findings.

As in many recent studies, ${ }^{4-10}$ some of the clinical features observed were nonspecific. Apart from scaling and erythema that were present in all cases, ${ }^{2-4,6,8,10}$ this study was in agreement with aforementioned analyses in highlighting pruritus as being the most common complaint from patients (100\%). The same studies indicate that palmoplantar keratoderma ${ }^{2,8}$ and changes in the nails $2,4,6,10$ were present in some psoriatic patients, indicating the importance of these findings in determining the diagnosis. This is also supported by the findings of this study, where such changes were characteristic of psoriatic erythroderma.

Temperatureof $38.5^{\circ} \mathrm{C}$ or higher in admission was another clinical finding in $34.5 \%$ of patients, comparable to the findings reported in previous reports. ${ }^{2-4,6,8,10}$ Temperature escalation is the result of barrier function damage, that allows the overlapping of bacterial infections, the development of secondary infections associated with hyperthermia, and thermoregulatory cutaneous function damage, all associated with body temperature disorder.

Three major changes in erythroderma were identified: increased erythrocyte sedimentation rate and C-reactive protein in the majority of the cases (93.1\%), leukocytosis in approximately half of the cases (43.9\%), and anaemia in a third of the cases (30.2\%). These results are in accordance with César et al., ${ }^{2}$ Fernandes et al., ${ }^{6}$ and Hulmani et al. ${ }^{8}$ (Table 2). ${ }^{3,4,10}$ 
Table 1.(A) Comparing results between earlier studies with the present study regarding age groups with the highest frequency, mean onset age, and male:female ratio. (B) Comparing results between earlier studies with the present study regarding the underlying aetiology of erythroderma.

\begin{tabular}{|c|c|c|c|c|c|c|c|c|c|}
\hline 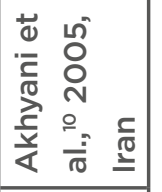 & $\frac{\$}{z}$ & $\stackrel{N}{\sigma}$ & $\begin{array}{l}\stackrel{\circ}{\ddot{\sigma}} \\
\stackrel{+}{n}\end{array}$ & & ள் & 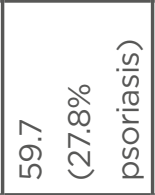 & $\begin{array}{l}\stackrel{0}{\sim} \\
\stackrel{\sim}{*}\end{array}$ & $\stackrel{\stackrel{M}{*}}{\rightleftharpoons}$ & $\stackrel{N}{N}$ \\
\hline 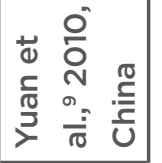 & $\frac{\varangle}{z}$ & $\underset{\Sigma}{\Sigma}$ & $\begin{array}{l}\stackrel{\circ}{\ddot{i n}} \\
\stackrel{i}{i}\end{array}$ & & $\infty$ & 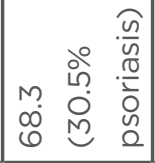 & $\stackrel{\circ}{\stackrel{\circ}{\perp}}$ & $\stackrel{\leftrightarrow}{+}$ & $\bar{\theta}$ \\
\hline 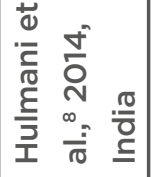 & $\begin{array}{l}8 \\
6 \\
1 \\
0 \\
0\end{array}$ & $\stackrel{\text { M }}{\text { Nin }}$ & 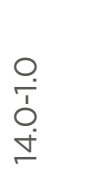 & & $\stackrel{\circ}{M}$ & 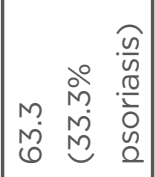 & \begin{tabular}{|l}
$\underline{\varphi}$ \\
$\dot{\varphi}$
\end{tabular} & $\stackrel{M}{M}$ & \begin{tabular}{|l}
0 \\
$\dot{\theta}$
\end{tabular} \\
\hline 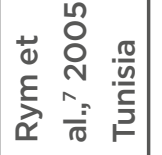 & $\begin{array}{l}0 \\
0 \\
1 \\
0 \\
1 \\
1\end{array}$ & $\begin{array}{l}\infty \\
\stackrel{\infty}{n} \\
\stackrel{n}{n}\end{array}$ & 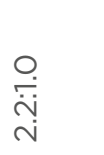 & & ০ & 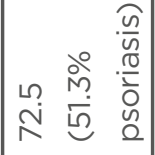 & $\stackrel{\stackrel{M}{F}}{=}$ & $\mid \begin{array}{l}\infty \\
\infty \\
\infty\end{array}$ & $\stackrel{\stackrel{n}{N}}{N}$ \\
\hline 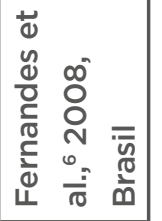 & $\begin{array}{l}0 \\
0 \\
1 \\
1 \\
1 \\
1\end{array}$ & $\begin{array}{l}\stackrel{L}{N} \\
\stackrel{n}{n}\end{array}$ & $\stackrel{\circ}{\stackrel{ }{\leftrightarrows}}$ & & $\stackrel{?}{\stackrel{2}{2}}$ & 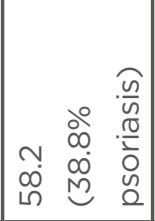 & $\stackrel{\infty}{\stackrel{\infty}{\sim}}$ & $\begin{array}{l}0 \\
0 \\
0\end{array}$ & $\stackrel{+}{\circ}$ \\
\hline 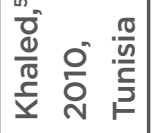 & $\begin{array}{l}0 \\
0 \\
1 \\
1 \\
0\end{array}$ & ถึં & 움 & $\infty$ & $\widetilde{\infty}$ & 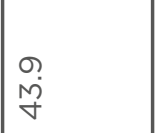 & $\underset{⿱ 亠}{\stackrel{\rho}{\sim}}$ & $\begin{array}{l}\stackrel{\rho}{\forall} \\
\dot{\nabla}\end{array}$ & $\begin{array}{l}\stackrel{\omega}{N} \\
\stackrel{N}{~}\end{array}$ \\
\hline 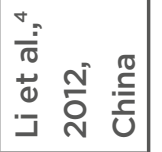 & \begin{tabular}{|l}
0 \\
0 \\
1 \\
1 \\
1 \\
\end{tabular} & \begin{tabular}{l}
0 \\
\multirow{\sim}{}{}
\end{tabular} & $\begin{array}{l}\text { 우 } \\
\text { ó } \\
\text { Mi }\end{array}$ & & 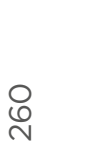 & 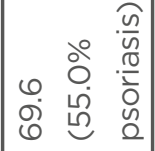 & 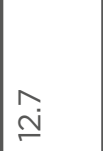 & $\stackrel{m}{N}$ & $\begin{array}{l}\stackrel{N}{ \pm} \\
\stackrel{5}{ \pm}\end{array}$ \\
\hline 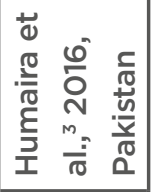 & $\begin{array}{l}0 \\
6 \\
1 \\
1 \\
1 \\
\end{array}$ & $\begin{array}{l}0 \\
\stackrel{\infty}{+} \\
\stackrel{+}{+}\end{array}$ & 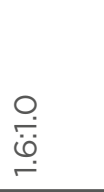 & & 음 & 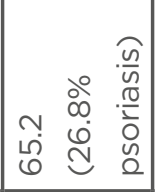 & 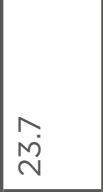 & 豆 & $\stackrel{\circ}{\circ}$ \\
\hline 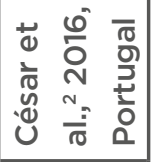 & $\begin{array}{l}0 \\
\infty \\
1 \\
1\end{array}$ & $\begin{array}{l}+ \\
\stackrel{+}{*}\end{array}$ & 足 & & 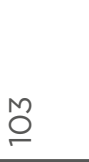 & 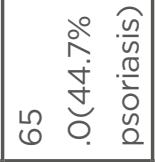 & $\begin{array}{l}\nabla \\
\infty \\
\infty\end{array}$ & $\begin{array}{l}\text { O} \\
\stackrel{\mathrm{I}}{ }\end{array}$ & 帛 \\
\hline 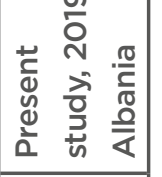 & \begin{tabular}{|l}
2 \\
$\frac{1}{6}$ \\
\end{tabular} & 渵 & $\begin{array}{l}\stackrel{0}{\dot{m}} \\
\stackrel{m}{\dot{m}}\end{array}$ & & $\stackrel{\varphi}{=}$ & 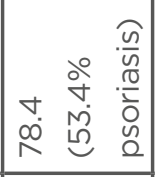 & $\stackrel{M}{\forall}$ & $\stackrel{\circ}{\circ}$ & \begin{tabular}{|l}
$\dot{\theta}$ \\
$\stackrel{\theta}{*}$
\end{tabular} \\
\hline 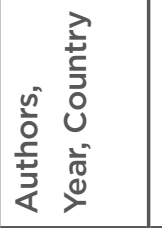 & 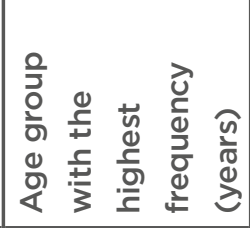 & 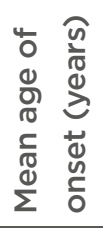 & 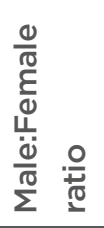 & & 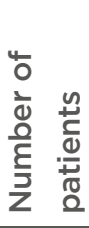 & 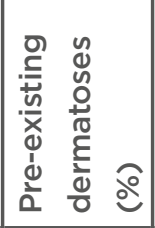 & 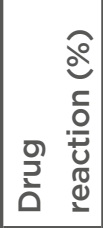 & 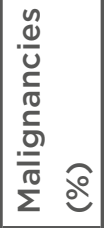 & 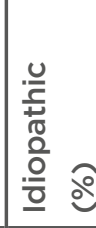 \\
\hline
\end{tabular}


Table 2: Comparing results between earlier studies with the present study regarding clinical and laboratory findings of erythroderma.

\begin{tabular}{|c|c|}
\hline Authors, year, country & Clinical and laboratory findings in admission \\
\hline Present study, 2019, Albania & $\begin{array}{l}\text { Pruritus: } 116 \text { pt, } 100.0 \% \\
\text { Temperature: } 40 \text { pt, } 34.5 \% \\
\text { Changes in the nails: } 32 \text { pt, } 27.6 \% \\
\text { Palmoplantar keratoderma: } 32 \text { pt, } 27.6 \% \\
\text { Increased ESR/CPR: } 108 \text { pt, } 93.1 \% \\
\text { Anaemia: } 35 \text { pt, } 30.2 \% \\
\text { Leukocytosis: } 51 \text { pt, } 43.9 \%\end{array}$ \\
\hline César et al., ${ }^{2} 2016$, Portugal & $\begin{array}{l}\text { Pruritus: } 100 \text { pt, } 97.1 \% \\
\text { Temperature: } 56 \text { pt, } 54.4 \% \\
\text { Palmoplantar keratoderma: } 52 \text { pt, } 50.5 \% \\
\text { Changes in the nails: } 44 \text { pt, } 42.7 \% \\
\text { Increased ERS/CRP: } 99 \text { pt, } 96.1 \% \\
\text { Anaemia: } 31 \text { pt, } 30.1 \% \\
\text { Leukocytosis: } 50 \text { pt, } 48.5 \%\end{array}$ \\
\hline Humaira et al., ${ }^{3}$ 2016, Pakistan & $\begin{array}{l}\text { Pruritus: } 97.5 \% \\
\text { Temperature: } 33.6 \% \\
\text { Lymphadenopathy: } 21.3 \% \\
\text { Oedema: } 14.4 \% \\
\text { Hyperkeratosis: } 7.2 \%\end{array}$ \\
\hline Li J et al., ${ }^{4} 2012$, China & $\begin{array}{l}\text { Pruritus: } 87.7 \% \\
\text { Temperature: } 40.0 \% \\
\text { Changes in nails: } 29.6 \% \\
\text { Oedema: } 37.7 \% \\
\text { Chills: } 31.2 \% \\
\text { Lymphadenopathy: } 19.2 \%\end{array}$ \\
\hline Fernandes et al., ${ }^{6}$ 2008, Brasil & $\begin{array}{l}\text { Pruritus: } 36 \text { pt, } 21.2 \% \\
\text { Chills: } 88 \text { pt, } 51.8 \% \\
\text { Lymphadenopathy: } 20 \text { pt, } 11.8 \% \\
\text { Temperature: } 14 \text { pt, } 8.2 \% \\
\text { Oedema: } 12 \text { pt, } 7.0 \% \\
\text { Anaemia: } 49 \text { pt, } 28.8 \% \\
\text { Leukocytosis: } 61 \text { pt, } 35.9 \% \\
\text { Nail changes: pitting, subungual keratosis, onycholysis, } \\
\text { Onychorrhexis: present, but not specified }\end{array}$ \\
\hline Hulmani et al., ${ }^{8} 2014$, India & $\begin{array}{l}\text { Pruritus: } 86.7 \% \\
\text { Temperature: } 43.3 \% \\
\text { Shivering: } 93.3 \% \\
\text { Palmoplantar keratoderma: } 46.5 \% \\
\text { Anaemia: } 15 \text { pt, } 50.0 \% \\
\text { Leukocytosis: } 12 \text { pt, } 40.0 \%\end{array}$ \\
\hline Akhyani $M$ et al., ${ }^{10} 2005$, Iran & $\begin{array}{l}\text { Pruritus: } 94 \text { pt, } 97.5 \% \\
\text { Temperature: } 32 \text { pt, } 33.6 \% \\
\text { Lymphadenopathy: } 20 \text { pt, } 1.3 \% \\
\text { Oedema: } 14 \text { pt, } 14.4 \% \\
\text { Hyperkeratosis: } 7 \text { pt, } 7.2 \% \\
\text { Changes in nails: } 31 \text { pt, } 32.6 \%\end{array}$ \\
\hline
\end{tabular}

CRP: C-reactive protein; ESR: erythrocyte sedimentation rate. 
In previous studies, 2,4-10 the benefit of biopsy was variable in determining the histological diagnosis. Despite the clinical presentation of erythroderma being relatively uniform, histopathological characteristics of underlying lesions are usually distinctive. ${ }^{12}$ In this study, cutaneous biopsy was needed to establish the final diagnosis in 86 (74.1\%) of the 105 patients (90.5\%) whom had cutaneous biopsy performed. This percentage is comparable to the results obtained from previous studies such as Khaled et al., ${ }^{5}$ with $77.0 \%$ of the cases conclusive; César et al., ${ }^{2} 66.4 \%$; Rym et al., ${ }^{7}$ 74.0\%; Bandyopadhyay et al., ${ }^{12} 52.0 \%$; Kondo et al., ${ }^{13} 72.5 \%$; and Hulmani et al., 8 80.0\%.

The main objective of this study was to determine the underlying aetiologies of erythroderma as a manifestation of systemic and cutaneous diseases. It was evidenced that the root cause of erythroderma in $78.4 \%$ of cases was the exacerbation of pre-existing dermatoses, with psoriasis constituting the most common aetiology in $53.4 \%$ of the cases $(n=62)$. Other present aetiologies included chronic eczema (3.4\%; $n=4)$, chronic dermatitis/spongiform dermatitis/psoriasiform dermatitis (10.3\%; $n=12)$, and subcorneal pustulosis (5.2\%; $n=6)$. The results obtained in the study correlate with previous clinical and aetiologic studies ${ }^{2-10}$ Cases with drug hypersensitivity-induced erythroderma represented a low percentage $(4.3 \% ; n=5)$ compared to the results of previous studies with values that varied from $11.3-23.7 \%^{2-10}$ (Table 1).

One of the most important challenges facing a dermatopathologist when evaluating skin biopsies from erythrodermic patients lies in the distinction between benign and malignant causes. ${ }^{14}$ The ability to differentiate benign (e.g., psoriasis, dermatitis, drug-induced) and malignant (e.g., Sézary syndrome, mycosis fungoides) forms of erythroderma require immunophenotypic study of their characteristics with the use of advanced antibody panels. ${ }^{15}$ Although clinically erythroderma is relatively uniform, immunohistochemical studies by Sigurdsson et al. ${ }^{16}$ showed a dermal infiltration of T-helper-2 cytokines in Sézary syndrome cases compared to a dermal infiltration of T-helper-1 cytokines in benign erythroderma cases. This denotes a different underlying pathogenic mechanism. ${ }^{17}$ In the past 10 years, new phenotypic and molecular markers of malignant Sézary cells were published, including loss of CD26 and CD7, and expression of Twist, EphA4, T-plastin, and CD158k/KIR3DL2, the latter allowing diagnosis in skin biopsies with quantitative reverse transcriptase-PCR. ${ }^{18-20}$ In addition, among the new markers, only $\beta$-catenin and JunB have proved to be suitable for immunohistochemistry on paraffin-embedded skin biopsies. ${ }^{21-24}$ Bellei et al. demonstrated $\beta$-catenin expression in $31 \%$ of mycosis fungoides and $70 \%$ of Sézary syndrome samples using immunohistochemistry. ${ }^{14}$ Among new markers of CTCL, JunB is not a sensitive feature but is specific for CTCL. ${ }^{14}$

In reference to our immunohistochemistry findings, the percentage of malignancies, whether cutaneous or internal, was $0.0 \%$, unlike the results obtained from the aforementioned series which indicated percentage values varying from $2.3-12.6 \%,{ }^{2-10}$ confirming the presence of malignancies such as CTCL; mycosis fungoides; Sézary Syndrome; leukaemia, nasopharyngeal, gastric, or pulmonary cancers; or histiocytosis (Table 1).

The final diagnosis of the underlying aetiology could not be determined in $16.4 \%$ of cases $(n=19)$, classifying this group under the idiopathic/ undefined category, also known as 'red man syndrome'. As the possibility of an undiagnosed CTCL was carefully considered, the nonspecific findings of histopathological examination favoured the diagnosis of idiopathic erythroderma. These idiopathic cases were found to be consistent with the reports in the aforementioned studies on erythroderma ranging between 6.1 and $16.6 \%$ (Table 1). ${ }^{4-10}$

Regarding the systemic disease group, no case with erythroderma as a manifestation of internal diseases was found. The data discussed in the above paragraphs show variations in relative percentages of different aetiologic and ethnic groups of erythroderma. These changes may be related to genetic, geographic, and social characteristics of patients with erythroderma.

It is important to understand the gravity of erythroderma. Although this condition is relatively rare, it has a significant mortality rate which is reported in several studies: Khaled et al. ${ }^{5}$ reported a mortality rate of 1.3 per 1,000 patients per year; Li et al., ${ }^{4}$ reported a mortality percentage of 3.2\%; and César et al., ${ }^{2}$ reported a mortality percentage of $5.8 \%$. In this study, no fatal case was detected 
(mortality: 0\%). This value only corresponds to the hospitalisation days of erythrodermic patients, as it does not include follow-up data.

This study provides important information on the characteristics of erythroderma in the authors' country, due to the importance of this pathology and the risk it may cause to the patient's life. A limitation of the study is the limited number of patients considered. Regardless of this, these findings finally create a base of development for further studies and research into this condition.

\section{CONCLUSIONS}

Erythroderma is a challenging condition with difficult diagnosis and reserved prognosis.

This study revealed a high percentage of secondary erythroderma with a pre-existing dermatosis, where psoriasis was the predominant aetiology and there was a relatively low percentage of primary erythroderma. Most of the clinical features and laboratory abnormalities were identical, irrespective of the aetiology. Histopathological examination was the most helpful tool for concluding the diagnosis, yielding a positive clinical correlation in the majority of cases. When no underling cause is found, careful follow-up is recommended.

\section{References}

1. Burton JL, Holden CA., "Eczema, lichenification and prurigo," Champion RH et al. (eds.), Text book of Dermatology (1998) Volume 1, 6th edition, Oxford: Blackwell Scientific Publications, pp.673-8.

2. César A et al. Erythroderma. A clinica and etiological study of 103 patients. J Dermatol Case Rep. 2016;10(1):1-9.

3. Humaira $T$ et al. A frequency of common etiologies of erythroderma in patients visiting a tertiary care hospital in Karachi. J Pak Assoc Dermatol. 2016;26(1).

4. Li J, Zheng H-Y. Erythroderma: A clinical and prognostic study. Dermatology. 2012;225(2):154-62.

5. Khaled A et al. Acquired erythroderma in adults: a clinical and prognostic study. J Eur Acad Dermatol Venereol. 2010;24(7):781-8.

6. Fernandes NC et al. [Erythroderma: clinical-laboratory and histopathological study of 170 cases]. An Bras Dermatol. 2008;83(6). doi: 10.1590/S036505962008000600005. (In Spanish).

7. Rym BM et al. Erythroderma in adults: a report of 80 cases. Int J Dermatol. 2005:44(9):731-5.

8. Hulmani $\mathrm{M}$ et al. Clinico-etiological study of 30 erythroderma cases from tertiary center in South India. Indian Dermatol Online J. 2014;5(1):25-9.

9. Yuan $X-Y$ et al. Erythroderma: a clinical-etiological study of 82 cases. Eur J Dermatol. 2010:20(3):373-7.

10. Akhyani $\mathrm{M}$ et al. Erythroderma: a clinical study of 97 cases. BMC Dermatol. 2005:5:5. doi: 10.1186/14715945-5-5.

11. Okoduwa $\mathrm{C}$ et al. Erythroderma: review of a potentially life-threatening dermatosis. Indian J Dermatol. 2009;54(1):1-6.

12. Bandyaopadhyay D et al. Seventy five cases of exfoliative dermatitis. Ind $J$ Dermatol. 1999;44(2):55-7.

13. Kondo RN et al. Exfoliative dermatitis: clinical and etiological study of 58 cases. An Bras Dermatol. 2006;81(3). doi: 0.1590/S0365 05962006000300004 .

14. Ram-Wolff $\mathrm{C}$ et al. Histopathologic diagnosis of lymphomatous versus inflammatory erythroderma: a morphologic and phenotypic study on 47 skin biopsies. Am J Dermatopathol. 2010;32(8):756-63.

15. Zip $C$ et al. The specificity of histopathology in erythroderma. $J$ Cutan Pathol. 1993:20(5):393-8.

16. Sigurdsson $\vee$ et al. Interleukin- 4 and Interferon-gamma expression of the dermal infiltrate in patients with erythroderma and mycosis fungoidesan immunohistochemical study. J Cutan Pathol. 2000:27(9):429-35.

17. Abel EA et al. Benign and malignant forms of erythroderma: cutaneous immunophenotypic characteristics. J Am Acad Dermatol. 1988:19(6):108995.

18. Bagot $\mathrm{M}$ et al. CD4(+) cutaneous T-cell lymphoma cells express the p140-killer cell immunoglobulin-like receptor. Blood. 2001;97(5):1388-91.

19. Poszepczynska-Guigné $\mathrm{E}$ et al. CD158k/KIR3DL2 is a new phenotypic marker of Sezary cells: relevance for the diagnosis and follow-up of Sezary syndrome. J Invest Dermatol. 2004:122(3):820-3.

20. Ortonne $\mathrm{N}$ et al. CD158K/KIR3DL2 transcript detection in lesional skin of patients with erythroderma is a tool for the diagnosis of Sézary syndrome. J Invest Dermatol. 2008;128(2):46572.

21. Bellei B et al. Frequent beta-catenin overexpression without exon 3 mutation in cutaneous lymphomas. Mod Pathol. 2004;17(10):1275-81.

22. Shaulian E, Karin M. AP-1 as a regulator of cell life and death. Nat Cell Biol. 2002;4(5):E131-6.

23. Rassidakis $\mathrm{GZ}$ et al. JunB expression is a common feature of CD3O+ lymphomas and lymphomatoid papulosis. Mod Pathol. 2005;18(10):1365-10.

24. Mao $X$ et al. Amplification and overexpression of JUNB is associated with primary cutaneous T-cell lymphomas. Blood. 2003;101(4): 1513-9. 